NASA/TM-2002-211554

\title{
Radiation Effects in a Semitransparent Gray Coating Heated by Convection and Cooled by Radiation
}

Charles M. Spuckler

Glenn Research Center, Gleveland, Ohio 
Since its founding, NASA has been dedicated to the advancement of aeronautics and space science. The NASA Scientific and Technical Information (STI) Program Office plays a key part in helping NASA maintain this important role.

The NASA STI Program Office is operated by Langley Research Center, the Lead Center for NASA's scientific and technical information. The NASA STI Program Office provides access to the NASA STI Database, the largest collection of aeronautical and space science STI in the world. The Program Office is also NASA's institutional mechanism for disseminating the results of its research and development activities. These results are published by NASA in the NASA STI Report Series, which includes the following report types:

- TECHNICAL PUBLICATION. Reports of completed research or a major significant phase of research that present the results of NASA programs and include extensive data or theoretical analysis. Includes compilations of significant scientific and technical data and information deemed to be of continuing reference value. NASA's counterpart of peerreviewed formal professional papers but has less stringent limitations on manuscript length and extent of graphic presentations.

- TECHNICAL MEMORANDUM. Scientific and technical findings that are preliminary or of specialized interest, e.g., quick release reports, working papers, and bibliographies that contain minimal annotation. Does not contain extensive analysis.

- CONTRACTOR REPORT. Scientific and technical findings by NASA-sponsored contractors and grantees.
- CONFERENCE PUBLICATION. Collected papers from scientific and technical conferences, symposia, seminars, or other meetings sponsored or cosponsored by NASA.

- SPECIAL PUBLICATION. Scientific, technical, or historical information from NASA programs, projects, and missions, often concerned with subjects having substantial public interest.

- TECHNICAL TRANSLATION. Englishlanguage translations of foreign scientific and technical material pertinent to NASA's mission.

Specialized services that complement the STI Program Office's diverse offerings include creating custom thesauri, building customized data bases, organizing and publishing research results ... even providing videos.

For more information about the NASA STI Program Office, see the following:

- Access the NASA STI Program Home Page at http://www.sti.nasa.gov

- E-mail your question via the Internet to help@sti.nasa.gov

- Fax your question to the NASA Access Help Desk at 301-621-0134

- Telephone the NASA Access Help Desk at 301-621-0390

- Write to: NASA Access Help Desk NASA Center for AeroSpace Information 7121 Standard Drive Hanover, MD 21076 
NASA/TM-2002-211554

\section{Radiation Effects in a Semitransparent Gray Coating Heated by Convection and Cooled by Radiation}

Charles M. Spuckler

Glenn Research Center, ('leveland, Ohio

Prepared for the

26th Annual International Conference on Advanced Ceramics and Composites sponsored by the American Ceramic Society

Cocoa Beach, Florida, January 13-18, 2002

National Aeronautics an

Space Administration

Glenn Research Center 
The Aerospace Propulsion and Power Program at NASA Glenn Research Center sponsored this work.

Available from

NASA Center for Aerospace Information 7121 Standard Drive

Hanover, MD 21076
National Technical Information Service 5285 Port Royal Road Springfield, VA 22100 


\title{
RADIATION EFFICTS IN A SEMITRANSPARENT GRAY COATING HEATED BY ('ONVECTION AND COOLED BY RADIATION
}

\author{
Charles M. Spuckler \\ National Aeronautics and Space Administration \\ Glenn Research Center \\ Cleveland, Ohio 44135
}

\begin{abstract}
A parametric study using a one dimensional model of a semitransparent gray thermal barrier coating was performed o gain an understanding of the role thermal radiation can play in the heat transferred. Some ceranic materials are semitransparent in the wavelength ranges were thermal radiation is important. Therefore, absorption, emission, and scattering of thermal radiation can affect the heat transfer through the coating. In this paper a one dimensional layer was used to model the heat transfer :rocess occurring in a burner test rig. The semitransparent layer is heated by a hot gas flowing cver its surface. The layer and substrate are cooled by radiation to the surroundings. The back side of the substrate is insulated. The coating is assumed to be gray (absorption and scattering coefficients are not function of wavelength). An absorption coefficient of $0.3 \mathrm{~cm}^{-1}$ and scattering coefficients of 0 (no scattering) and $100 \mathrm{~cm}^{-1}$ (isotropic scattering) were used. The thickness an $\rfloor$ thermal conductivity of the layer are varied. The results show that the temperatures are affectcd by the properties of the semitransparent layer and the emissivity of the substrate. The substrate and surface temperatures are presented. The apparent temperature an optical pyrometer would read for the emitted energy is also given. An apparent thermal conductivity was calculated for the layer.
\end{abstract}

\section{INTRODUCTION}

Some thermal bar er coatings (TBCs), such as zirconia are partially transparent to thermal radiation refs. 1 and 2 . In semitransparent materials, both thermal radiation and heat conduction determine the temperature and energy transferred. The radiation heat transfer depends on the absorption and scatterin:s coefficients, and the refractive index of the material. The emission inside the material depends on the refractive index squared. Since the energy that passes through an interface cannot exceed that of a black body some of the energy inside the material is totally reflected back into the layer. This can have a significant effect on the temperatures in the material. An effective thermal conductivity, which includes both conduction and radiation, depends on a number of factors, such as substrate emissivity, the absorption and scattering properties, temperature level and gradient, and the tempcrature of the surroundings. Determining a single value for the effective thermal conductivity, that can be used for all conditions may not be possible. To determine the heat transferred through a semi-transparent $\mathrm{TBC}$, the conduction equation using the intrinsic thermal conductivity along with the radiative transfer equation or an approximate form of the radiative transfer equation should be used. The work on heat transfer in semitransparent materials with index of refraction greater than one has been reviewed partially in refs. 3 and 4 . In these papers the thermal behavior of absorbing, cmitting and scattering materials with refractive indices greater than one are predicted. In refs. 5 and 6 approximate solutions were developed. 
To design more effective TBCs the roles surface reflections, absorption, emission, and scattering along with heat conduction play in heat transfer must be understood. To determine these effects, the absorption and scattering coefficients, and refractive index of the material as a function of wavelength and temperature must be known. The scattering characteristics of the TBC will depend on the structure of the material. The intrinsic thermal conductivity also has to be determined.

A burner test rig is often used to evaluate TBCs. To obtain an understanding of how radiation affects a TBC in a burner rig test, a semitransparent material with absorption coefficient, $a=0.3 \mathrm{~cm}^{-1}$, scattering coefficients, $\sigma_{\mathrm{s}}=0$ (non-scattering idealized structure) and $\sigma_{\mathrm{s}}=100 \mathrm{~cm}^{-1}$ (scattering splat structure) and a refractive index, $\mathrm{n}=2.1$, is considered. These values are in the range of those for zirconia in the wavelengths were it is semitransparent, refs. 1 and 2. The absorption and scattering coefficients, refs. 1 and 2 , were determined from experimental data and are a function of wavelength. In ref. 2, data were obtained at temperatures up to $699 \mathrm{~K}$. The scattering coefficient does vary significantly with wavelength. The scattering coefficient, ref. 2 , was highest over $300 \mathrm{~cm}^{-1}$ near $0.7 \mu \mathrm{m}$ and decreased to about $18 \mathrm{~cm}^{-1}$ at $5 \mu \mathrm{m}$. For this analysis, the TBC is assumed to be gray, the absorption and scattering coefficients and refractive index are not functions of wavelength. The intrinsic thermal conductivity and the thickness of the layer are varied. The substrate and TBC surface temperatures are presented. The apparent temperature an optical pyrometer would measure from the emitted energy is also given for a gray layer. An effective thermal conductivity is calculated using the TBC surface and substrate temperatures. The effective thermal conductivity is compared to the intrinsic thermal conductivity used in the calculations.

MODEL

The model used, fig. 1, is a semi-infinite insulated flat surface coated with a semitransparent

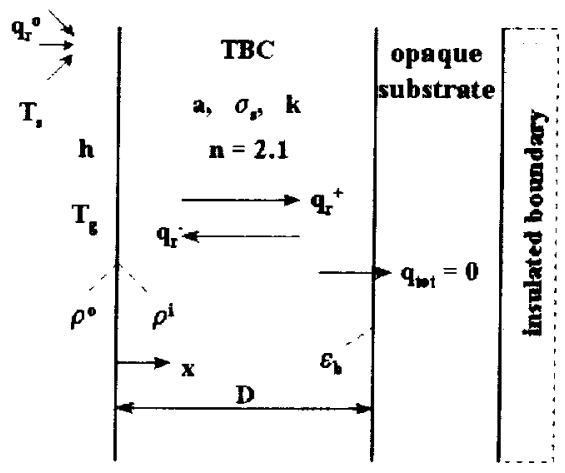

Fig. 1 Heat transfer model

material. A two flux method to examine the effect of various parameters on the thermal behavior of a semitransparent coating on a opaque substrate insulated on its back side was derived in ref. 7 . The coating is heated by convection and cooled by radiation. The interface reflections are diffuse. A nondimensional parametric study was performed in ref. 7 to determine the effects of various parameters on the heat transfer characteristics of the coating. That parametric study is extended to a burner rig test. The equations used from ref. 7 are in appendix A. The prediction of the thermal behavior of a TBC depends on how accurate the thermal and radiative properties are known.

The coating is heated by a gas, $T_{\text {as }}=1600 \mathrm{~K}$, flowing over its surface. The convective heat transfer coefficient, $h$, is $100 \mathrm{~W} /\left(\mathrm{m}^{2} \mathrm{~K}\right)$. This heat is conducted through the coating to the substrate. The heated coating radiates to itself, the surroundings, and the substrate. There is no heat transfer 
through the insulated substrate. Heat is removed by radiation from the layer and substrate to the surroundings $T_{s}=295 \mathrm{~K}$. If the optical thickness, $\kappa_{D}=\left(\sigma_{s}+a\right) D$, of the layer is small, the layer and substrate will radiate energy to the surroundings. If the layer is optically thick, only volumes near the gas-TBC interface will ridiate to the surroundings.

\section{EFFECT OF LAYER TIIICKNESS AND THERMAL CONDUCTIVITY}

The effects of coatir $g$ thermal conductivity and layer thickness are shown in figures 2 and 3 . The

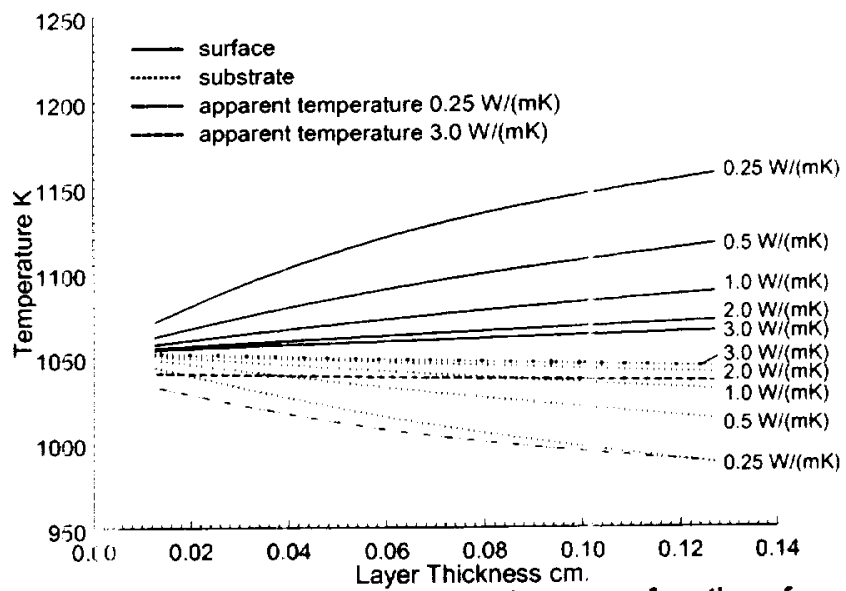

Fig. 2 surface and substrate temperatures as a function of layer t ickness $a=0.3 \mathrm{~cm}^{-1}, \sigma_{s}=0, \varepsilon_{b}=0.8$, and $n=2.1$

emissivity of the substrite, $\varepsilon_{\mathrm{b}}$ is 0.8 . Figure 2 is for no scattering. The surface temperature (solid lines) increases and the substrate temperature (dotted lines) decreases with thickness. For a given thickness, the surface temperature decreases and the substrate temperature increases as the thermal conductivity increases. For a $0.0127 \mathrm{~cm}(0.005 \mathrm{in}$. $)$ thick layer the temperature drop through the layer is $2.3 \mathrm{~K}$ for $\mathrm{k}=3.0 \mathrm{~W} /(\mathrm{mK})$ and $26.7 \mathrm{~K}$ for $\mathrm{k}=0.25 \mathrm{~W} /(\mathrm{mK})$. For a $0.127 \mathrm{~cm}(0.05$ in. $)$ thick layer the temperature drop thr $\mathrm{sugh}$ the layer increases to $21.0 \mathrm{~K}$ for $\mathrm{k}=3.0 \mathrm{~W} /(\mathrm{mK})$ and $169.5 \mathrm{~K}$ for $\mathrm{k}=$

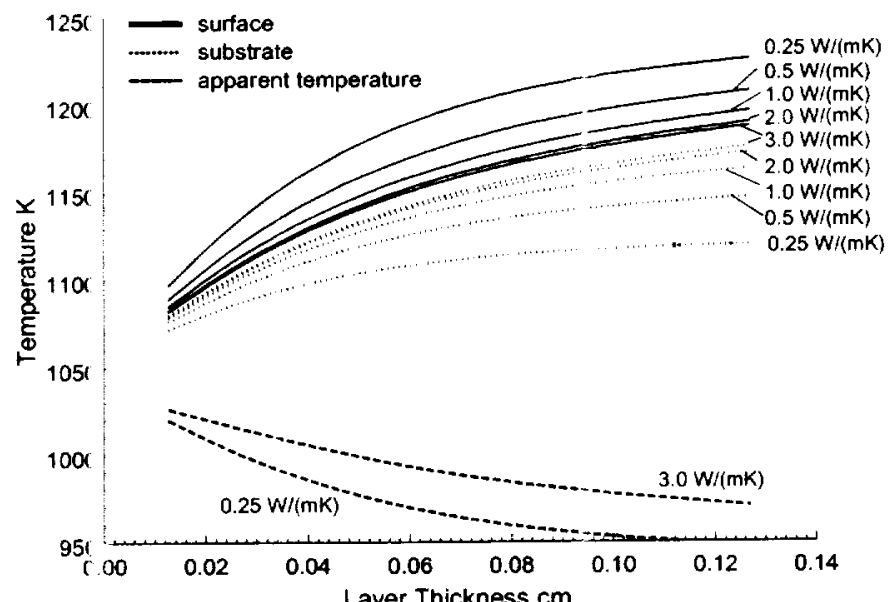

Fig. 3 Surface and substrate temperature as a function of layer thick: ress $\mathrm{a}=0.3 \mathrm{~cm}^{-1}, \sigma_{\mathrm{s}}=100 \mathrm{~cm}^{-1}, \varepsilon_{\mathrm{b}}=0.8$ and $\mathrm{n}=2.1$ 
$0.25 \mathrm{~W} /(\mathrm{mK})$. The temperature profiles in figure 2 are nearly linear for high thermal conductivities indicating conduction may be the dominate mode of heat transfer in the semi-transparent layer. For low thermal conductivities, the temperature curves become non-linear indicating radiation is playing a role in the heat transfer inside the TBC.

Isotropic scattering, $\sigma_{\mathrm{s}}=100 \mathrm{~cm}^{-1}$ is added in figure 3. Scattering increased the temperature in the layer. Radiant energy emitted by the substrate and the layer is scattered in all directions. Some of the energy scattered back is absorbed increasing the temperature of the substrate and the coating. For this amount of a scattering the substrate temperature increases with coating thickness as contrast to the substrate temperature decreasing with thickness for a non-scattering coating. For a $0.0127 \mathrm{~cm}$ thick layer the temperature drop through the layer is $2.2 \mathrm{~K}$ for $\mathrm{k}=3.0 \mathrm{~W} /(\mathrm{mK})$ and $25.2 \mathrm{~K}$ for $\mathrm{k}=0.25 \mathrm{~W} /(\mathrm{mK})$. This temperature drop is almost the same as the non-scattering layer. For a $0.127 \mathrm{~cm}$ thick layer, the temperature drop through the layer is $11.6 \mathrm{~K} \mathrm{for} \mathrm{k}=3.0$ $\mathrm{W} /(\mathrm{mK})$. This is about $55 \%$ of the temperature drop for the non-scattering layer. For $\mathrm{k}=0.25$ $\mathrm{W} /(\mathrm{mK})$, the temperature drop is $106.2 \mathrm{~K}$ which is $63 \%$ of the temperature drop in the nonscattering layer. Scattering causes the temperature drop in a layer to decrease and heat to be retained in the coating and substrate.

The apparent surface temperatures for the low, $0.25 \mathrm{~W} /(\mathrm{mK})$, and high, $3 \mathrm{~W} /(\mathrm{mK})$, thermal conductivity semitransparent coatings are shown in figures 2 and 3 . Here the apparent surface temperature is defined as the temperature a pyrometer operating over all wavelengths would measure for the energy emitted by a gray layer. For the layer with no scattering, figure 2, the apparent temperature (dashed and dots-dashed lines) is closer to the substrate temperature than the surface temperature. For a coating with scattering, figure 3, the apparent temperature (dashed line) is considerably lower than the substrate temperature. Scattering lowers the apparent surface temperature. To obtain the most accurate temperature measurement with an optical pyrometer, a wavelength where the coating is opaque has to be used.

\section{EFFECTIVE THERMAL CONDUCTIVITY}

An effective thermal conductivity was determined assuming that all the heat transfer into the layer by convection was conducted to the substrate. So, $q_{\text {convection }}$ equals $q_{\text {conduction. The heat }}$ transferred by convection is

$$
\mathrm{q}_{\text {convection }}=\mathrm{h} \times\left(\mathrm{T}_{\text {gas }}-\mathrm{T}_{\text {surface }}\right)
$$

The effective thermal conductivity is

$$
\mathrm{k}_{\text {effective }}=\frac{\mathrm{q}_{\text {conducion }} \times \mathrm{D}}{\mathrm{T}_{\text {surface }}-\mathrm{T}_{\text {substrate }}}
$$

The surface and substrate temperatures calculated previously using the two-flux solution were used to determine the effective thermal conductivity. The effective thermal conductivities and the percent difference between the effective thermal conductivity and the intrinsic thermal conductivity used in the two-flux calculation are in figures 4 and 5. The dotted line in the figures is for $k_{\text {effective }}=k_{\text {intrinsic }}$ and is presented as a reference. The effective thermal conductivities are larger than the intrinsic thermal conductivities. The 0.0127 and $0.0254 \mathrm{~cm}$ thick layer data are not presented in the figures. For these thicknesses the percent difference between the intrinsic and effective thermal conductivities was less than $5 \%$ for the conditions used. The effective thermal conductivities increase with the thickness of the layer. The largest percent differences between the effective and intrinsic thermal conductivities occur for the thickest layers and the lowest intrinsic 
thermal conductivities. The heat conducted through the layer to the substrate is opposite to the net radiative heat flow to the surroundings. The radiative energy scattered back to the substrate will cause the scattering layer to have a higher substrate temperature than the non-scattering layer. This results in a higher effective thermal conductivity in the scattering layer as shown in figure 5.

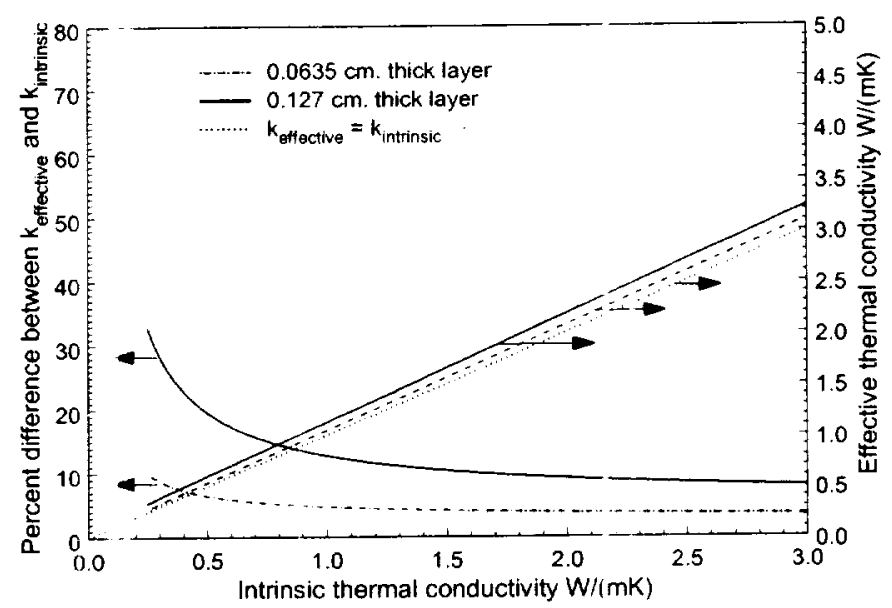

Fig. 4 intrinsic and effective thermal conductivities non-scattering layer $a=0.3 \mathrm{~cm}^{-1}, \sigma_{s}=0, \varepsilon_{b}=0.8, n=2.1, T_{g}=1600 \mathrm{~K}, T_{s}=295 \mathrm{~K}$

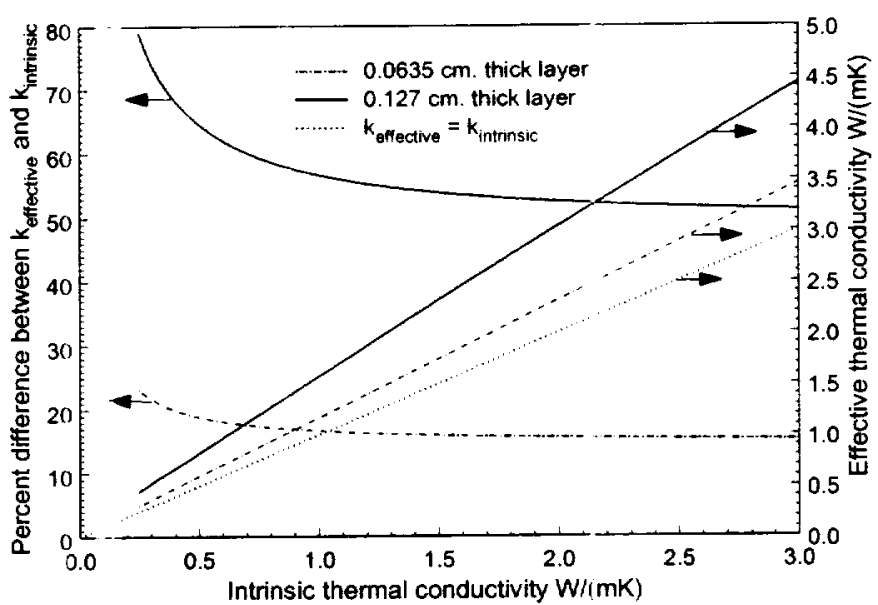

Fig. 5 Intrinsic and effective thermal conductivities scattering layer $a=0.3 \mathrm{~cm}^{-1}, \sigma_{s}=100 \mathrm{~cm}^{-1}, \varepsilon_{\mathrm{b}}=0.8, n=2.1, T_{\mathrm{g}}=1600 \mathrm{~K}, \mathrm{~T}_{\mathrm{s}}=295 \mathrm{~K}$

In Tables I and II the effect of changing the gas or surroundings temperatures, or the substrate emissivity is investigated for two layer thicknesses. For the $0.0127 \mathrm{~cm}(0.005 \mathrm{in}$.) non-scattering and scattering layers, cl anging the gas or surroundings temperature by $500 \mathrm{~K}$ or the emissivity to 0.2 had a slight effect on the effective thermal conductivity. For the $0.127 \mathrm{~cm}$ thick layer these changes have a significint effect on the effective thermal conductivity especially for the scattering layer. The lowest percent difference between the intrinsic and effective thermal conductivities was $20.1 \%$ for decreas ng the gas temperature by $500 \mathrm{~K}$ for the non-scattering $0.127 \mathrm{~cm}$ thick layer. The greatest perzent difference was $91.4 \%$ when the substrate emissivity was decrease to 0.2 for the scattering lay er. 
Table I Effect of gas temperature, surrounding temperature or substrate emissivity nonscattering layer

\begin{tabular}{|c|c|c|c|c|c|c|c|c|}
\hline $\begin{array}{c}\text { Thick- } \\
\text { ness } \\
\mathrm{cm}\end{array}$ & $\begin{array}{c}\mathrm{T}_{\text {gas }} \\
\mathrm{K}\end{array}$ & $\begin{array}{c}\mathrm{T}_{\text {surround }} \\
\mathrm{K}\end{array}$ & $\varepsilon_{\mathrm{b}}$ & $\begin{array}{c}\mathrm{T}_{\text {surface }} \\
\mathrm{K}\end{array}$ & $\begin{array}{c}\mathrm{T}_{\text {subsrrate }} \\
\mathrm{K}\end{array}$ & $\begin{array}{c}\mathrm{k}_{\text {intrinsic }} \\
\mathrm{W} /(\mathrm{mK})\end{array}$ & $\begin{array}{c}\mathrm{k}_{\text {effective }} \\
\mathrm{W} /(\mathrm{mK})\end{array}$ & $\begin{array}{c}\text { Percent } \\
\text { Difference } \\
\text { in } \mathrm{k}\end{array}$ \\
\hline 0.0127 & 1600 & 295 & 0.8 & 1070.66 & 1044.00 & 0.25 & 0.2522 & 0.88 \\
\hline 0.0127 & 1100 & 295 & 0.8 & 864.19 & 852.30 & 0.25 & 0.2519 & 0.76 \\
\hline 0.0127 & 1600 & 795 & 0.8 & 1123.55 & 1099.57 & 0.25 & 0.2523 & 0.92 \\
\hline 0.0127 & 1600 & 295 & 0.2 & 1151.36 & 1129.38 & 0.25 & 0.2592 & 3.68 \\
\hline & & & & & & & & \\
\hline 0.127 & 1600 & 295 & 0.8 & 1156.95 & 987.49 & 0.25 & 0.3320 & 32.80 \\
\hline 0.127 & 1100 & 295 & 0.8 & 898.51 & 813.28 & 0.25 & 0.3002 & 20.08 \\
\hline 0.127 & 1600 & 795 & 0.8 & 1202.51 & 1055.55 & 0.25 & 0.3435 & 37.40 \\
\hline 0.127 & 1600 & 295 & 0.2 & 1177.56 & 1036.21 & 0.25 & 0.3798 & 51.92 \\
\hline
\end{tabular}

Table II. Effect of gas temperature, surrounding temperature or substrate emissivity scattering layer

\begin{tabular}{|c|c|c|c|c|c|c|c|c|}
\hline $\begin{array}{c}\text { Thick- } \\
\text { ness } \\
\mathrm{cm}\end{array}$ & $\begin{array}{c}\mathrm{T}_{\text {gas }} \\
\mathbf{K}\end{array}$ & $\begin{array}{c}\mathrm{T}_{\text {surrourd }} \\
\mathrm{K}\end{array}$ & $\varepsilon_{\mathrm{b}}$ & $\begin{array}{c}\mathrm{T}_{\text {surface }} \\
\mathrm{K}\end{array}$ & $\begin{array}{c}\mathrm{T}_{\text {substrate }} \\
\mathrm{K}\end{array}$ & $\begin{array}{c}\mathrm{k}_{\text {intrinsic }} \\
\mathrm{W} /(\mathrm{mK})\end{array}$ & $\begin{array}{c}\mathrm{k}_{\text {effective }} \\
\mathrm{W} /(\mathrm{mK})\end{array}$ & $\begin{array}{c}\text { Percent } \\
\text { Difference } \\
\text { in } \mathrm{k}\end{array}$ \\
\hline 0.0127 & 1600 & 295 & 0.8 & 1096.68 & 1071.44 & 0.25 & 0.2533 & 1.36 \\
\hline 0.0127 & 1100 & 295 & 0.8 & 880.85 & 869.85 & 0.25 & 0.2530 & 1.24 \\
\hline 0.0127 & 1600 & 795 & 0.8 & 1144.75 & 1121.95 & 0.25 & 0.2536 & 1.44 \\
\hline 0.0127 & 1600 & 295 & 0.2 & 1166.96 & 1145.84 & 0.25 & 0.2604 & 4.16 \\
\hline & & & & & & & & \\
\hline 0.127 & 1600 & 295 & 0.8 & 1225.66 & 1119.43 & 0.25 & 0.4475 & 79.00 \\
\hline 0.127 & 1100 & 295 & 0.8 & 949.20 & 902.51 & 0.25 & 0.4102 & 64.08 \\
\hline 0.127 & 1600 & 795 & 0.8 & 1257.00 & 1161.24 & 0.25 & 0.4549 & 81.96 \\
\hline 0.127 & 1600 & 295 & 0.2 & 1230.12 & 1131.94 & 0.25 & 0.4785 & 91.40 \\
\hline
\end{tabular}

\section{CONCLUSIONS}

Thermal radiation can play a significant role in the heat transfer in semitransparent coatings. A parametric study was performed to obtain an understanding of radiation effects in a burner rig test of a TBC. A one dimensional model is used. The coating is heated by a hot gas flowing over its surface and cooled by radiating to the surroundings. There is no heat transfer through the backside of the material which simulates a symmetric centerline boundary condition for the specimen. An absorption coefficient of $0.3 \mathrm{~cm}^{-1}$ and scattering coefficients of 0 (no scattering) and $100 \mathrm{~cm}^{-1}$ (isotropic scattering) were used. The coating is assumed to be gray, that is the properties are not a function of wavelength. The thickness and thermal conductivity of the layer are varied. The results show that the heat transfer is a function of the optical properties of the coating and the substrate. Increasing the thermal conductivity or decreasing the layer thickness results in a smaller temperature drop in the layer. Scattering increases the temperature level in the coating and substrate and decreases the temperature drop though the coating. With no scattering, the substrate temperature decreased with thickness. With scattering, $\sigma_{\mathrm{s}}=100 \mathrm{~cm}^{-1}$, heat is trapped in the coating, causing the substrate temperature to increase with thickness. An effective thermal conductivity can be significantly different from the intrinsic thermal conductivity for thick scattering TBCs. If an optical pyrometer is used for temperature measurements, the material must be opaque at the measurement wavelength if accurate results are to be obtained. 


\section{Appendix A}

The equations in ret. 7 were used. The differential equation for the temperature distribution in the absorbing, emitting, and scattering TBC model used is

$$
\frac{d T}{d x}= \pm\left[\begin{array}{l}
\frac{2 k}{k}(1.0-\Omega)\left\{\frac{4}{5} n^{2} \sigma\left[T^{5}(x)-T^{5}(0)\right]+\frac{3}{2} k \kappa\left[T^{2}(x)-T^{2}(0)\right]-3 C \kappa[T(x)-T(0)]\right\}+ \\
\left\{\frac{h}{k}\left[T_{g}-T(0)\right]\right\}
\end{array}\right\}^{\frac{1}{2}}
$$

where $\sigma$ is the Stefan-Boltzmann constant, $\kappa=\left(\sigma_{\mathrm{s}}+\mathrm{a}\right), \Omega:=\sigma_{\mathrm{s}} / \kappa$, and

$$
C=h T(0)+\frac{1}{3 K}\left\{4 \frac{1-\rho^{0}}{1-\rho^{i}} q_{r}^{0}+2 \frac{1+\rho^{i}}{1-\rho^{i}} h\left[T_{z}-T(0)\right]\right\}
$$

For surface heating a po itive value of the square root is used.

For optically thin layers, there is a temperature gradient at the interface between the TBC and substrate, and the bound iry condition at $\mathrm{x}=\mathrm{D}$ is

$$
\left.\frac{\mathrm{dT}}{\mathrm{dx}}\right|_{\mathrm{x}=\mathrm{D}}=\frac{1}{\mathrm{k}} \frac{2 \varepsilon_{\mathrm{b}}}{2-\varepsilon_{\mathrm{b}}}\left[\frac{3}{4} \mathrm{C} \kappa-\frac{3}{4} \kappa \mathrm{kT}(\mathrm{D})-\mathrm{n}^{2} \sigma \mathrm{T}^{4}(\mathrm{D})\right]
$$

If the layer is optically hick the temperature gradient is only near the gas-TBC interface and the boundary condition at $\mathrm{x}-\mathrm{D}$ becomes

$$
\left.\frac{\mathrm{dT}}{\mathrm{dx}}\right|_{x=\mathrm{D}}=0
$$

To obtain the tempe ature distribution in the layer, the temperature of the surface of the TBC, $\mathrm{T}(0)$, is assumed. Equation (1) for $\mathrm{dT} / \mathrm{dx}$ is solved using a Runge-Kutta method. The boundary condition $\mathrm{dT} / \mathrm{dx}$ at $\mathrm{x}=\mathrm{D}$, equation (3) or (4) is checked to see if it is satisfied. If it is not satisfied $\mathrm{T}(0)$ is adjusted until the boundary condition is satisfied.

The equation for tle apparent surface temperature of the layer, which is the temperature a pyrometer would measu e for the emitted energy, can be written as

$$
\sigma_{\text {app }}=\frac{1}{\sigma^{\frac{1}{4}}\left(1-\rho^{\circ}\right)^{\frac{1}{4}}}\left\{q_{r}^{\circ}\left(1-\rho^{\circ}\right)+h\left[T_{g}-T(0)\right]\right\}^{\frac{1}{4}}
$$

The interface refle tion and transmission were determined using integrated averages of the Fresnel relations ref. 8 rige 115. 


$$
\begin{aligned}
& \tau^{\circ}(n)=1-\rho^{\circ}(n)=\frac{1}{2}-\frac{(3 n+1)(n-1)}{6(n+2)^{2}}-\frac{n^{2}\left(n^{2}-1\right)^{2}}{\left(n^{2}+1\right)^{3}} \ln \left(\frac{n-1}{n+1}\right) \\
& +\frac{2 n^{3}\left(n^{2}+2 n-1\right)}{\left(n^{2}+1\right)\left(n^{4}-1\right)}-\frac{8 n^{4}\left(n^{4}+1\right)}{\left(n^{2}+1\right)\left(n^{4}-1\right)^{2}} \ln (n)
\end{aligned}
$$

This assumes the medium is a non-attenuating dielectric, that is the complex part of refractive index is neglected. This is a reasonable assumption if the absorption is not large ref. 9. The complex part of the refractive index determines the absorption coefficient. If the absorption coefficient is large the complex index of refraction must be included in the relations for the reflectivity and transmission of the interface.

The internal reflection, which includes energy at angles greater than the critical angle for total reflection is ref. 10

$$
\rho^{i}(n)=1-\frac{\tau^{0}(n)}{n^{2}}
$$




\section{REFERENCES}

${ }^{1}$ Wahiduzzaman, S. and Morel, T., Effect of Translucence of Engineering Ceramics on Heat Transfer in Diesel Engin:s, ORNL/Sub/88-22042/2, April 1992.

${ }^{2}$ Makino, T., Kunito no, T., Sakai, I., and Kinoshita, H., Thermal Radiation Properties of Ceramic Materials, Heat Transfer , Japanese Research, 13 [4] 33-50 (1984).

${ }^{3}$ Spuckler, C.M., an:I Siegel R., "Refractive Index and Scattering Effects on Radiative Behavior of a Semitransparent Lay er," Journal of Thermophysics and Leat Transfer, 7 [2] 302-310 (1993).

${ }^{4}$ Spuckler, C.M., and Siegel R., "Refractive Index and Scattering Effects on Radiation in a Semitransparent Laminated Layer," Journal of Thermophysics and Heat Transfer, 8 [2] 193-201 (1994).

${ }^{5}$ Siegel, R., and Spurkler, C.M., "Approximate Solution Methods for Spectral Radiative Transfer in High Refractive Inde، Layers," International Joumal of Heat and Mass Transfer, 37 [Suppl. 1] 403-413 (1994).

${ }^{6}$ Spuckler, C.M., al d Siegel R., "Two-Flux and Diffusion Methods for Radiative Transfer in Composite Layers," Joun nal of Heat Transfer, 118 [1] 218-222 (1996).

${ }^{7}$ Siegel, R., and Syuckler, C.M., "Temperature Distributions in Semitransparent Coating-A Special Two-Flux Solution," Journal of Thermophysics and Ieat Transfer, 10 [1] $39-46$ (1996).

${ }^{8}$ Siegel, R. and Fowell, J.R., Thermal Radiation Heat Transfer, 3rd ed., Hemisphere, Washington, DC, 1992.

${ }^{9}$ Cox, R.L., "Fundamentals of Thermal Radiation in Ceramic Materials," pp. 83-101 in Symposium on Thermal Radiation of Solids, edited by S. Katzoff, NASA SP-55, 1965.

${ }^{10}$ Richmond, J.C., "Relation of Emittance to Other Optical Properties," Journal of Research of the National Bureau of Standards-C. Engineering and Instrumentation, 67C [3], 1963, 217-226 (1963). 


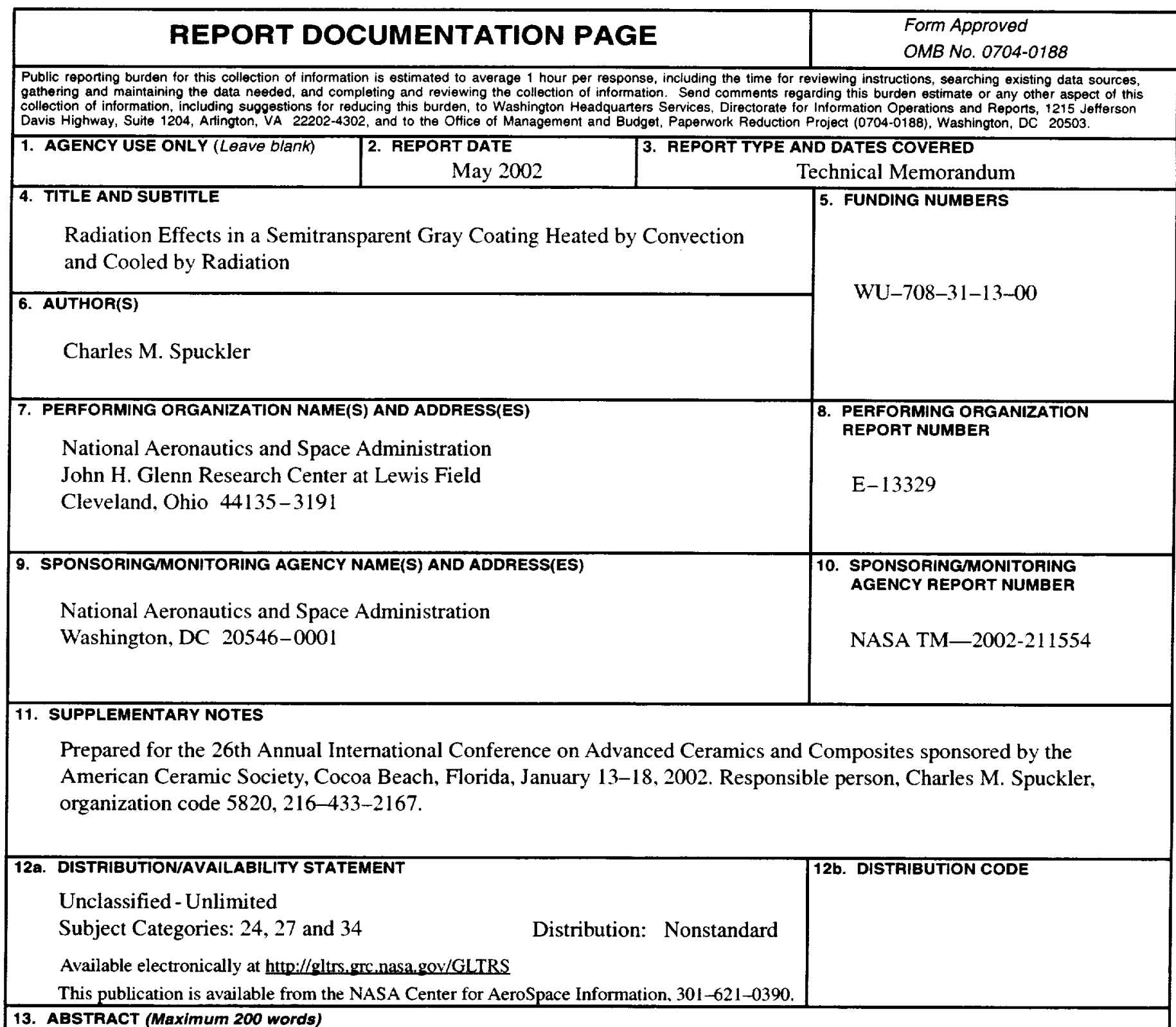

13. ABSTRACT (Maximum 200 words)

A parametric study using a one dimensional model of a semitransparent gray thermal barrier coating was performed to gain an understanding of the role thermal radiation can play in the heat transferred. Some ceramic materials are semitransparent in the wavelength ranges were thermal radiation is important. Therefore, absorption, emission, and scattering of thermal radiation can affect the heat transfer through the coating. In this paper, a one dimensional layer was used to model the heat transfer process occurring in a burner test rig. The semitransparent layer is heated by a hot gas flowing over its surface. The layer and substrate are cooled by radiation to the surroundings. The back side of the substrate is insulated. The coating is assumed to be gray (absorption and scattering coefficients are not function of wavelength). An absorption coefficient of $0.3 \mathrm{~cm}^{-1}$ and scattering coefficients of 0 (no scattering) and $100 \mathrm{~cm}^{-1}$ (isotropic scattering) were used. The thickness and thermal conductivity of the layer are varied. The results show that the temperatures are affected by the properties of the semitransparent layer and the emissivity of the substrate. The substrate and surface temperatures are presented. The apparent temperature an optical pyrometer would read for the emitted energy is also given. An apparent thermal conductivity was calculated for the layer.

14. SUBJECT TERMS

Thermal barrier coatings; Radiation; Conduction; Absorption; Scattering

15. NUMBER OF PAGES 15

\begin{tabular}{|c|c|c|}
\hline $\begin{array}{c}\text { 17. SECURITY CLASSIFICATION } \\
\text { OF REPORT } \\
\text { Unclassified }\end{array}$ & $\begin{array}{c}\text { 18. SECUAITY CLASSIFICATION } \\
\text { OF THIS PAGE } \\
\text { Unclassified }\end{array}$ & $\begin{array}{c}\text { 19. SECURITY CLASSIFICATION } \\
\text { OF ABSTRACT } \\
\text { Unclassified }\end{array}$ \\
\hline
\end{tabular}

